\title{
Differences in healthy food supply and stocking practices between small grocery stores, gas-marts, pharmacies and dollar stores
}

\author{
Caitlin Eicher Caspi ${ }^{1, *}$, Jennifer E Pelletier ${ }^{2}$, Lisa Harnack ${ }^{2}$, Darin J Erickson ${ }^{2}$ and \\ Melissa N Laska \\ 'Department of Family Medicine and Community Health, Program in Health Disparities Research, University of \\ Minnesota, 717 Delaware St. SE, Minneapolis, MN 55414, USA: ${ }^{2}$ Division of Epidemiology and \\ Community Health, University of Minnesota, Minneapolis, MN, USA
}

Submitted 30 December 2014: Final revision received 9 July 2015: Accepted 21 August 2015: First published online 28 September 2015

\begin{abstract}
Objective: Little is known about the practices for stocking and procuring healthy food in non-traditional food retailers (e.g. gas-marts, pharmacies). The present study aimed to: (i) compare availability of healthy food items across small food store types; and (ii) examine owner/manager perceptions and stocking practices for healthy food across store types.

Design: Descriptive analyses were conducted among corner/small grocery stores, gas-marts, pharmacies and dollar stores. Data from store inventories were used to examine availability of twelve healthy food types and an overall healthy food supply score. Interviews with managers assessed stocking practices and profitability.

Setting: Small stores in Minneapolis and St. Paul, MN, USA, not participating in the Special Supplemental Nutrition Program for Women, Infants, and Children.

Subjects: One hundred and nineteen small food retailers and seventy-one store managers.

Results: Availability of specific items varied across store type. Only corner/small grocery stores commonly sold fresh vegetables (63\% v. $8 \%$ of gas-marts, $0 \%$ of dollar stores and $23 \%$ of pharmacies). More than half of managers stocking produce relied on cash-and-carry practices to stock fresh fruit (53\%) and vegetables $(55 \%)$, instead of direct store delivery. Most healthy foods were perceived by managers to have at least average profitability.

Conclusions: Interventions to improve healthy food offerings in small stores should consider the diverse environments, stocking practices and supply mechanisms of small stores, particularly non-traditional food retailers. Improvements may require technical support, customer engagement and innovative distribution practices.
\end{abstract}

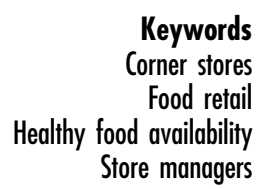

Keywords

Food retail

Store managers
In the urban food environment, small food stores, sometimes referred to as 'corner stores', are common in low-income areas $^{(1-5)}$. Small food stores are the most frequent food sources for urban residents after supermarkets ${ }^{(6)}$. Visits to these stores have been described as routinized, accessible and convenient ${ }^{(1,6,7)}$, and as such, small food stores play an important role in food exposure ${ }^{(5,7-9)}$. Small food store purchases may be a particularly important source of food for lower-income adults ${ }^{(6)}$. It has been estimated that $20 \%$ of Supplemental Nutrition Assistance Program (SNAP) transactions for low-income households occurred at convenience stores or other small food stores ${ }^{(10)}$, and SNAP benefit redemptions at convenience stores occur with much greater frequency in low-income urban areas compared with high-income suburban areas ${ }^{(11)}$. Such shopping patterns are important to health, as frequent small food store shopping has been associated with unhealthy food purchases, lower vegetable intake and increased obesity risk ${ }^{(6,12-16)}$.

Previous studies have indicated that, in general, the supply of healthy items within small food stores is limited. For example, in a study of small food stores in four urban US areas, only $50 \%$ of stores sold at least one variety of fresh fruit or vegetable ${ }^{(17)}$. A separate study found that the healthfulness of food offered by small food stores was significantly lower than offerings by medium-sized grocers and supermarkets ${ }^{(18)}$. The availability of healthy items has also been shown to vary substantially by factors like store location and store size, where the smallest stores have 
demonstrated the most limited selection of healthy food items $^{(17,19,20)}$.

Additional research is needed to better understand the supply of healthy food in small stores, especially given the range of retailers currently selling food and beverages. Specifically, very little work has characterized small, non-traditional food retailers - including gas-marts, pharmacies and dollar stores - that are not considered to be mainstream grocers, but often sell a significant amount of food and beverages. Recent work has focused on evaluating the nutritional quality of foods available in these non-traditional stores ${ }^{(18,21-25)}$. Such work has focused mainly on the abundance of unhealthy items like snacks, candy and sugar-sweetened beverages in these store types ${ }^{(21,23,24)}$. How stores like pharmacies, gas-marts and dollar stores may compare with traditional corner stores or larger grocery stores - particularly in their supply of healthy food - is unknown, even while small food stores are increasingly a target of intervention ${ }^{(1,26-28)}$.

Managers of pharmacies, gas-marts and dollar stores may play a key role in determining the supply of healthy food in their stores. In more traditional small grocery stores, factors such as customer demand, profitability and the availability of retail space have been cited as highpriority considerations for managers in making stocking decisions $^{(29,30)}$. These considerations may differ by small store type depending on their customer base, degree of corporate autonomy and access to food distribution systems. Major distributors may be reluctant to offer store delivery or stock small orders in smaller and independently owned stores ${ }^{(31,32)}$. Yet, to date, there is generally very little understanding of how such manager decisions and procurement practices might vary across different kinds of store.

To address these gaps in the literature, the purpose of the present study was to: (i) compare the availability of healthy food items in different types of stores, including corner/small grocery stores, gas-marts, pharmacies and dollar stores, in an urban setting; and (ii) examine small food store manager perceptions and stocking practices related to healthy food, including the extent to which these vary across store type.

\section{Methods}

\section{Sample}

A sampling plan was developed to assess foods available in smaller food retail outlets within the city limits of Minneapolis and St. Paul, MN, USA that were not participating in the Special Supplemental Nutrition Program for Women, Infants, and Children (WIC), a voluntary programme that sets minimum stocking requirements for healthy foods. The study was conducted as part of a larger pre-baseline evaluation of non-WIC-participating stores in both cities. These stores were potential targets for a city ordinance regulating minimum stocking requirements for licensed grocery stores outside the downtown core commercial districts in Minneapolis and comparable stores in St. Paul. Recognizing the contribution of non-traditional retailers such as gas-marts, dollars stores and pharmacies in the sale of food and beverages (and their potential role in improving the availability of healthy food in communities), the proposed ordinance unambiguously targeted these store types along with other non-WIC grocers ${ }^{(33)}$. The study involved randomly selecting small food stores from a list of all stores with grocery licences in both cities. The list of stores was obtained from relevant licensing agencies (i.e. the Minneapolis Health Department for Minneapolis stores and the Minnesota Department of Agriculture for St. Paul stores). Stores were deemed ineligible if they were supermarkets or accepted WIC benefits (because these stores were presumed to already meet minimum stocking requirements), if they had invalid licensing addresses, or if they were located in core downtown commercial districts (because these stores would not be expected to stock a wide array of foods). Other stores that would not be reasonably expected to stock a minimal variety of foods were also excluded, including those that had $\leq 9.29 \mathrm{~m}^{2}\left(\leq 100 \mathrm{ft}^{2}\right)$ of retail space (such as auto-repair shops selling limited snacks), small vendors in market areas (e.g. produce stands), and liquor or specialty stores (e.g. spice shops).

Out of 310 eligible stores, we visited a random selection of 172 stores and completed store audits (described below) in 119 stores (sixty in Minneapolis, fifty-nine in St. Paul). Of the fifty-three stores where audits were not completed, twenty-three were identified as ineligible upon visiting the store in-person (e.g. due to new participation in WIC), six were out of business, one was under renovation, ten could not be located at the listed address and thirteen refused to participate. Among the 119 stores with completed store audits, all store owners or managers were invited to participate in a brief interview assessing stocking practices; seventy-one managers agreed to complete the interview (response rate: $60 \%$ ). The sub-sample of stores completing the manager interview was similar to the larger sample in terms of store type and store size.

\section{Data collection}

Store audits were conducted on weekdays between 09.45 and 16.30 hours. In teams of two, data collectors entered stores, identified themselves and asked for permission to conduct the audit and interview. All stores invited to participate received a mailed letter in advance describing the study.

\section{Store audit}

The store audit was based on a tool developed at the Yale Rudd Center for Food Policy and Obesity and previously used to evaluate the impact of 2009 WIC policy revisions in small food stores ${ }^{(34)}$. The standardized inventory is 
adapted from the Nutrition Environment Measure Survey in Stores (NEMS-S) tool and has demonstrated good interrater and test-retest reliability. The Rudd Center adaptation focused on healthy, staple foods and substituted some WIC-approved items for some non-WIC foods (e.g. frozen dinners were not included; eggs and canned fish were included). Our study team slightly modified the Rudd Center tool to align with local food stocking practices and other store features of interest (e.g. some package sizes were modified; infant formula was not included). The inventory measured the availability and price of sixty-nine specific items, including fresh, frozen and canned fruits and vegetables with no added ingredients (other than salt in canned products), $100 \%$ juice, wholegrain-rich bread, whole-wheat or corn tortillas, brown rice, wholegrain-rich cereals in packages $\geq 340 \mathrm{~g}(\geq 12 \mathrm{oz})$, low-fat milk and milk substitutes, dry beans and lentils in packages $\leq 454 \mathrm{~g}$ ( $\leq 16 \mathrm{oz}$ ), cheese in packages $\geq 227 \mathrm{~g}$ ( $\geq 8 \mathrm{oz}$ ), eggs in dozen containers, plain nut butters in $\leq 510 \mathrm{~g}(\leq 18 \mathrm{oz})$ containers, canned fish in water, and tofu, as well as some less healthy comparison items (e.g. white bread, whole milk). The audit also assessed the number of varieties of milk; fresh, frozen and canned fruits and vegetables; cheese; canned beans; wholegrain-rich cereals; wholegrain-rich bread; brown rice; and wholegrain tortillas, as well as the quality of twenty specific fresh fruits and vegetables. Inter-rater reliability was assessed in thirtythree stores. Agreement for sixty-one of sixty-nine items was excellent (91-100\% agreement), and good for eight additional items (82-88\% agreement), including regularfat cheddar cheese, $100 \%$ juice, canned peas and beans, white bread and dry lentils. Overall agreement was good (86\%) for produce quality scores.

Data were used to create a Healthy Food Supply (HFS) score, summarizing availability, price, quality and variety of inventory $^{(34)}$. The summary score had a possible range of $0-31$, and included scoring for fourteen food categories. Higher scores indicate healthier food supplies. This score has previously been used in research in both WIC and non-WIC stores ${ }^{(34)}$, and it is based on a similar NEMSbased score - the Healthy Food Availability Index - which has been positively associated with diet quality ${ }^{(20)}$.

\section{Manager interview}

Interviews were conducted with store owners or managers (referred to as 'managers' from here forward for readability) at the time of the store audit or during a follow-up visit to the store. Interview questions were adapted from a previous assessment of stocking practices conducted among small, WIC-authorized food stores in eight US cities $^{(29)}$. Managers completed the close-ended face-toface interview with trained study staff and were asked how important each of a list of factors was in their decision to stock certain foods in their stores ('not at all important', 'somewhat important' or 'very important'). They were also asked about a variety of stocking practices related to specific healthy and unhealthy products, including a list of twelve healthy food categories: fresh, frozen and canned fruit; fresh, frozen and canned vegetables; $100 \%$ juice; wholegrain-rich bread; brown rice; white corn tortillas; wholegrain-rich cereal; and skimmed/low-fat milk. Managers were asked, 'How much profit do you make from selling' each of the twelve products (response categories were 'very little', 'lower than average', 'average', 'above average', 'best of all foods' or 'not offered'), as well as, 'Please let me know how you mostly obtain these products for your store: self-supply/cash and carry, a general distributor or direct store delivery?' Self-supply included items that were independently purchased from warehouses, club stores and/or larger supermarkets $v$. items obtained from a general distributor or direct store delivery, which included products that were ordered and delivered to the store. Finally, managers were asked questions about demographics and store characteristics (number of aisles, whether the store accepted SNAP benefits).

\section{Analyses}

Descriptive statistics on store characteristics, availability of healthy foods, HFS scores and manager-reported perceptions and stocking practices were calculated after stratifying by store type (corner/small grocery stores, gas-marts, pharmacies and dollar stores). Analyses were conducted in the statistical software package Stata version $13 \cdot 1$.

\section{Results}

Small food stores were categorized as corner stores/small grocery stores (39\%), gas-marts (43\%), dollar stores (8\%) or pharmacies (11\%). Table 1 presents store characteristics across store type. Most corner/small grocery stores and gas-marts had one or two cash registers and six or fewer aisles, whereas most pharmacies and dollar stores had more than two registers and at least seven aisles. Most

Table 1 Characteristics of surveyed stores $(n 119)$ in Minneapolis and St. Paul, MN, USA

\begin{tabular}{lcccc}
\hline Characteristic & $\begin{array}{c}\text { Corner or small } \\
\text { grocery }\end{array}$ & $\begin{array}{c}\text { Gas- } \\
\text { mart }\end{array}$ & $\begin{array}{c}\text { Dollar } \\
\text { store }\end{array}$ & Pharmacy \\
\hline Total $n$ & 46 & 51 & 9 & 13 \\
$\%$ & 39 & 43 & 8 & 11 \\
Number of cash registers (\%) & & & & \\
1 & 78 & 24 & 0 & 15 \\
2 & 16 & 49 & 38 & 0 \\
3 or more & 7 & 27 & 63 & 85 \\
Number of aisles (\%) & & & & \\
1 or 2 & 24 & 16 & 0 & 8 \\
3 to 6 & 58 & 61 & 13 & 8 \\
$\quad 7$ or more & 18 & 24 & 88 & 85 \\
Accepts SNAP benefits (\%) & 69 & 78 & 100 & 92 \\
Open 24 h (\%) & 0 & 26 & 0 & 23 \\
Point-of-sales transaction tracking & 22 & 70 & 89 & 92 \\
$\quad$ system (\%) & & & & \\
\hline
\end{tabular}

SNAP, Supplemental Nutrition Assistance Program. 
stores accepted SNAP benefits regardless of the store type. Corner stores/small grocery stores were unlikely to have a point-of-sales transaction tracking system (22\%), whereas this was common in other types of store. Approximately one-quarter of gas-marts (26\%) and pharmacies (23\%) were open $24 \mathrm{~h}$, whereas no corner stores/small grocery stores or dollar stores were.

HFS scores and the availability of healthy options by store type are presented in Table 2. Average HFS scores ranged from 8.0 (at gas-marts) to 11.0 (at pharmacies). Corner stores/small groceries exhibited notably wide variability in their HFS scores, with scores ranging from 0 to 24.5 and a SD of $6 \cdot 2$. Corner stores/small groceries were by far the most likely to sell fresh vegetables of any type of store (63\%), and most also stocked fresh fruit (61\%). Gasmarts were the most likely to sell fresh fruit (71\%), but rarely carried vegetables $(8 \%)$. Few pharmacies stocked fresh fruits or vegetables (23\%), and no dollar store

Table 2 Availability of specific healthy foods and Healthy Food Supply (HFS) score, by store type ( $n$ 119), Minneapolis and St. Paul, MN, USA

\begin{tabular}{|c|c|c|c|c|}
\hline & $\begin{array}{l}\text { Corner or small } \\
\text { grocery }\end{array}$ & $\begin{array}{l}\text { Gas- } \\
\text { mart }\end{array}$ & $\begin{array}{l}\text { Dollar } \\
\text { store }\end{array}$ & Pharmacy \\
\hline \multicolumn{5}{|c|}{ Availability (\% of stores with item in stock) } \\
\hline \multicolumn{5}{|c|}{ Fruit and vegetables } \\
\hline Fresh fruit & $60 \cdot 9$ & $70 \cdot 6$ & 0.0 & $23 \cdot 1$ \\
\hline Fresh vegetables & $63 \cdot 0$ & $7 \cdot 8$ & 0.0 & $23 \cdot 1$ \\
\hline Frozen fruit & $17 \cdot 4$ & 0.0 & $33 \cdot 3$ & 0.0 \\
\hline Frozen vegetables & $47 \cdot 8$ & $3 \cdot 9$ & 44.4 & 0.0 \\
\hline Canned fruit & 43.5 & $49 \cdot 0$ & $100 \cdot 0$ & 84.6 \\
\hline Canned vegetables & $78 \cdot 3$ & $80 \cdot 4$ & $100 \cdot 0$ & $92 \cdot 3$ \\
\hline $100 \%$ juice & $45 \cdot 7$ & $56 \cdot 9$ & $55 \cdot 6$ & 53.8 \\
\hline \multicolumn{5}{|l|}{ Wholegrain-rich products } \\
\hline $\begin{array}{l}\text { Wholegrain-rich/ } \\
\text { whole-wheat bread }\end{array}$ & $17 \cdot 4$ & $19 \cdot 6$ & $33 \cdot 3$ & $76 \cdot 9$ \\
\hline Brown rice & $39 \cdot 1$ & $9 \cdot 8$ & $55 \cdot 6$ & 0.0 \\
\hline White corn tortillas & $32 \cdot 6$ & $7 \cdot 8$ & $22 \cdot 2$ & 0.0 \\
\hline Wholegrain-rich cereal & $54 \cdot 3$ & $84 \cdot 3$ & $77 \cdot 8$ & $92 \cdot 3$ \\
\hline \multicolumn{5}{|l|}{ Dairy } \\
\hline Low-fat milk & $56 \cdot 5$ & $92 \cdot 2$ & $66 \cdot 7$ & 84.6 \\
\hline \multicolumn{5}{|l|}{ HFS score } \\
\hline Mean & $8 \cdot 8$ & $8 \cdot 0$ & $9 \cdot 2$ & $11 \cdot 0$ \\
\hline SD & $6 \cdot 2$ & 3.5 & 2.3 & $4 \cdot 2$ \\
\hline Range & $0-24.5$ & $0-14.5$ & $7-13.5$ & $1-17.5$ \\
\hline
\end{tabular}

stocked fresh produce. In general, pharmacies and dollar stores stocked a narrower range of healthy options, but more consistently had certain items, such as canned fruits and vegetables and wholegrain-rich cereal, compared with other stores. Frozen fruits and vegetables were not sold in pharmacies or gas-marts, except for $4 \%$ of gas-marts that sold frozen vegetables.

Refrigerator/freezer space, profitability and customer requests were reported to be 'very important' by a majority of stores in influencing stocking decisions across all store types (Table 3 ). The availability and prices at wholesale clubs was not reported to be very important in making stocking decisions at dollar stores and pharmacies; by contrast, for nearly two-thirds (64\%) of corner stores/small grocery stores, wholesale club availability and prices were very important in making stocking decisions.

Table 4 presents manager reports about stocking healthy items, including the perceived profitability of items and the distribution methods used for each product. Results are presented across all stores due to small cell sizes when stratified by store type (i.e. data were based on a sample of seventy-one manager interviews and only included stores that reported stocking each item). Overall, the majority of store managers perceived most healthy items to be average in terms of profitability, with the exception of fresh fruit, which was perceived to be below average in terms of profitability for $54 \%$ of managers. Items that were considered to be above average profitability by the largest proportion of managers were white corn tortillas (32\%), juice (28\%), wholegrain-rich bread (21\%) and wholegrain-rich cereals (20\%).

Most healthy items were obtained through direct store delivery or a general distributor (Table 4). The only exception was fresh fruits and vegetables, where more than half of managers reported obtaining them by selfsupply/cash and carry (53\% and 55\%, respectively) rather than direct store delivery or a general distributor. Exploratory analyses by store type (not shown) suggest that, for the items that they do stock, dollar stores and pharmacies rely on direct store delivery or general distributors $100 \%$ of the time.

Table 3 Percentage of store managers $(n 71)$ who reported various factors to be 'very important' in their decision to stock certain foods, overall and by store type, Minneapolis and St. Paul, MN, USA

\begin{tabular}{|c|c|c|c|c|c|c|}
\hline \multirow[b]{2}{*}{ Factor } & \multicolumn{2}{|c|}{ All stores } & \multirow{2}{*}{$\frac{\text { Corner or small grocery }}{\%}$} & \multirow{2}{*}{$\frac{\text { Gas-mart }}{\%}$} & \multirow{2}{*}{$\frac{\text { Dollar store }}{\%}$} & \multirow{2}{*}{$\frac{\text { Pharmacy }}{\%}$} \\
\hline & $n$ & $\%$ & & & & \\
\hline Refrigerator/freezer availability & 51 & $72 \cdot 9$ & $75 \cdot 9$ & $72 \cdot 0$ & 83.3 & $60 \cdot 0$ \\
\hline Profitability & 51 & $71 \cdot 8$ & $69 \cdot 0$ & $84 \cdot 6$ & $83 \cdot 3$ & $40 \cdot 0$ \\
\hline Customer requests & 48 & $67 \cdot 6$ & $82 \cdot 8$ & $57 \cdot 7$ & $66 \cdot 7$ & $50 \cdot 0$ \\
\hline Direct store delivery & 34 & $49 \cdot 3$ & $46 \cdot 4$ & $52 \cdot 0$ & $50 \cdot 0$ & $50 \cdot 0$ \\
\hline Ability to return products to suppliers & 33 & $47 \cdot 1$ & $46 \cdot 4$ & $57 \cdot 7$ & $50 \cdot 0$ & $20 \cdot 0$ \\
\hline How well similar foods sell & 31 & $44 \cdot 3$ & $53 \cdot 6$ & $23 \cdot 1$ & $66 \cdot 7$ & $60 \cdot 0$ \\
\hline Availability/prices at wholesale clubs & 28 & $40 \cdot 0$ & $64 \cdot 3$ & 34.6 & 0.0 & $10 \cdot 0$ \\
\hline Suppliers' recommendations & 17 & $24 \cdot 3$ & 21.4 & $23 \cdot 1$ & $50 \cdot 0$ & $20 \cdot 0$ \\
\hline Other & 13 & $59 \cdot 1$ & $42 \cdot 9$ & $57 \cdot 1$ & $50 \cdot 0$ & 83.3 \\
\hline
\end{tabular}


Table 4 Owner/manager perceptions of profit from healthy foods and healthy food stocking practices, Minneapolis and St. Paul, MN, USA

\begin{tabular}{|c|c|c|c|c|c|c|}
\hline & \multirow[b]{3}{*}{$n^{*}$} & \multicolumn{3}{|c|}{ Perception of profit } & \multicolumn{2}{|c|}{ Stocking practice } \\
\hline & & $\begin{array}{l}\text { Above average or } \\
\text { best of all foods }\end{array}$ & Average & Below average & $\begin{array}{l}\text { General distributor or } \\
\text { direct store delivery† }\end{array}$ & $\begin{array}{l}\text { Cash and carry/ } \\
\text { self-supply } \ddagger\end{array}$ \\
\hline & & $\%$ & $\%$ & $\%$ & $\%$ & $\%$ \\
\hline White corn tortillas & 25 & $32 \cdot 0$ & $44 \cdot 0$ & $24 \cdot 0$ & $76 \cdot 0$ & $24 \cdot 0$ \\
\hline $100 \%$ juice & 61 & $27 \cdot 9$ & $49 \cdot 2$ & $23 \cdot 0$ & $89 \cdot 1$ & $10 \cdot 9$ \\
\hline Wholegrain-rich/whole-wheat bread & 56 & $21 \cdot 4$ & $48 \cdot 2$ & $30 \cdot 4$ & $81 \cdot 4$ & $18 \cdot 6$ \\
\hline Wholegrain-rich cereal & 54 & $20 \cdot 4$ & $57 \cdot 4$ & $22 \cdot 2$ & $77 \cdot 6$ & $22 \cdot 4$ \\
\hline Fresh vegetables & 26 & $19 \cdot 2$ & $42 \cdot 3$ & 38.5 & $44 \cdot 8$ & $55 \cdot 2$ \\
\hline Low-fat milk & 56 & $14 \cdot 3$ & $41 \cdot 1$ & $44 \cdot 6$ & $85 \cdot 0$ & $15 \cdot 0$ \\
\hline Brown rice & 25 & $12 \cdot 0$ & $48 \cdot 0$ & $40 \cdot 0$ & $88 \cdot 0$ & $12 \cdot 0$ \\
\hline Fresh fruit & 43 & $11 \cdot 6$ & 34.9 & 53.5 & $46 \cdot 8$ & $53 \cdot 2$ \\
\hline Canned vegetables & 56 & 8.9 & 62.5 & 28.6 & 88.3 & $11 \cdot 7$ \\
\hline Frozen fruit & 20 & $5 \cdot 0$ & $60 \cdot 0$ & $35 \cdot 0$ & 88.9 & $11 \cdot 1$ \\
\hline Frozen vegetables & 21 & $4 \cdot 8$ & $57 \cdot 1$ & $38 \cdot 1$ & $76 \cdot 2$ & $23 \cdot 8$ \\
\hline Canned fruit & 53 & 1.9 & $69 \cdot 8$ & $28 \cdot 3$ & 87.9 & $12 \cdot 1$ \\
\hline
\end{tabular}

${ }^{*}$ Refers only to stores that reported selling each type of healthy food. Sample sizes for stocking practice questions may be slightly higher because some managers refused to answer the questions about profit.

†ltems that were obtained from a general distributer or direct store delivery, which included products ordered and delivered to the store.

†ltems that were independently purchased from warehouses, club stores and/or larger supermarkets.

\section{Discussion}

The present study is the first one to compare healthy food supply across a range of small food store types, including small grocery stores, dollar stores, pharmacies and gas-marts. Our findings indicate that the supply of healthy food items in a variety of types of small food store is limited, particularly fresh and frozen fruits and vegetables at gas-marts, pharmacies and dollars stores. Overall HFS scores averaged 8.0 to 11.0 across store type out of a total possible score of 31 . These scores are similar to HFS scores found in a previous study of WIC and non-WIC small food stores in Connecticut, where the average HFS score was $9 \cdot 35$ in $2010^{(34)}$. Considering the HFS as one descriptive measure of healthy food availability that incorporates price, variety and quality, our results add to evidence from other studies that there is room for improvement in most small food stores ${ }^{(17,18)}$.

Our results support a tailored approach in efforts to address shortfalls in supply given the variability in store offerings. For instance, we hypothesize that dollar stores, none of which sold fresh produce, may require procurement and storage assistance for these items, whereas in gas-marts a larger consideration might be finding adequate space, including freezer space for frozen produce. Additional research is needed to confirm these findings and identify appropriate approaches for different types of store. A tailored approach may be particularly important for more traditional corner stores and small groceries (i.e. those stores primarily selling food and beverages only), which demonstrated substantial heterogeneity in their offerings. For instance, these stores were by far the most likely to sell fresh produce compared with other store types, yet nearly $40 \%$ did not stock any fresh fruit or vegetables.
For small businesses, profitability is unquestionably an important consideration in deciding what to sell. Our findings indicate that most healthy items were perceived by managers to have average profitability compared with other types of product. Wholegrain-rich items (in particular, tortillas, wholegrain-rich bread and wholegrain-rich cereal) were perceived to be among the most profitable of healthy items among the stores that sell them. The scarcity of these products in small stores suggests that - in addition to procurement assistance - more motivation is needed for managers to stock such items.

A variety of strategies could be used to address barriers and motivation for stocking healthy foods. Store infrastructure enhancements, or low-interest loans or grants for additional cooler space could be an important starting point, given the importance of space cited by managers. Customer demand also was reported to be an important consideration for managers in determining what to sell. To address this need, business and promotion training for managers might yield better marketing of healthier options to customers. Such efforts would be most effective if coupled with community engagement strategies to increase customer demand and hold stores to a higher standard in the healthfulness of the products they offer. Increased demand might encourage managers to consider participating in voluntary government assistance programmes like WIC or Healthy Food Financing Initiatives $^{(35)}$. Alternatively, store managers might be responsive to local policies that set requirements for healthy items or prohibit the sale of certain unhealthy options. Local ordinances addressing diet and obesity have increasingly come under consideration in the USA, such as taxes on sugar-sweetened beverages $^{(36)}$ and the sale of staple foods ${ }^{(33)}$. Our results give an indication of how easily stores could respond - and the kinds of challenges they 
would encounter - were they to have incentives or requirements for stocking healthier items.

Securing access to adequate distribution channels for healthy items is another critical step in enabling managers to increase healthy food supply in their stores. In our sample, fresh fruits and vegetables were least likely to be delivered through a general distributor or direct store delivery; instead, more than half of managers relied on cash-and-carry practices to stock their store, consistent with findings from other studies ${ }^{(29,30,32)}$. Self-supply has been cited as a key challenge for store managers in supplying fresh produce ${ }^{(31)}$, as it requires managers to make frequent trips to a larger store and pay retail prices. Wholesale produce distributors may be reluctant to sell and deliver to smaller stores, where the volume of orders is small, may change frequently and may result in increased delivery costs for the wholesaler ${ }^{(32)}$. Because of this, pharmacies and dollar stores, most of which were part of national chains in the current study, may be particularly well-positioned to make improvements in their fresh fruit and vegetable supply. If they decided to stock fresh, perishable foods, these stores could have access to large distribution systems unavailable to independent corner stores.

Despite the supply and stocking patterns observed in the current study, it remains unclear precisely how much control store managers have over their merchandise and how that control might be determined by corporate restrictions or other powers, including contracts or obligations to industry representatives from beverage, salty snack or other companies. Future research should formally examine what kinds of constraints on decision making may exist from both corporate and other industry influences at each of these store types. Better understanding these influences could help to identify tailored opportunities to change stocking patterns - for instance, identifying which areas of shelf or refrigerator space managers have control over or discussing healthier substitutes for merchandise with industry representatives. These types of control might operate differently in chain stores compared with independently owned stores. More specifically, independent stores may be able to make autonomous decisions about the items they supply or industry contracts. By contrast, many supply decisions and contracts in chain stores might be determined by corporate headquarters, meaning major changes in stocking decisions could potentially be more difficult to negotiate, but could potentially be more far-reaching once implemented voluntarily or through licensing requirements.

The present study has a number of limitations. First, data were collected from a limited geographic region in urban Minnesota. Thus, results may not be generalizable to other areas of the USA or beyond, where small food stores may play a different role in the food environment. The HFS scores reported here can only be used descriptively, and cannot be compared against larger stores, as scores for larger grocery stores have not been reported in the literature. Our sample size was small for some store types (i.e. dollar stores and pharmacies), and nearly all pharmacies and dollar stores were part of national chains. Furthermore, not all of the managers in our store sample responded to the interview, and data only reflect responses for the items that stores sold, which in some cases was low (e.g. frozen items, brown rice, corn tortillas). When assessing stocking practices, we also collected limited data on unhealthy food to serve as a comparison for healthy food; in future work, it would be informative to include unhealthy products to directly compare profitability and procurement methods. Finally, our data from managers represent their perceptions only and provided limited insight into the decision-making process of managers; objective data on profit margins or sales data, or more nuanced or open-ended questions and response options, might offer additional explanations of the stocking decisions of managers. Despite these limitations, the study is among the first to characterize healthy food supply among retailers that are often overlooked, but may play an important role in the retail food landscape in both urban and rural environments ${ }^{(23,25,37,38)}$.

Characterizing small food store supply and manager perceptions is an important step in developing interventions to improve the supply of healthy food in urban neighbourhoods. In order for managers at these stores to consider increasing their healthy food supply, they may require both technical support in supplying healthy food as well as community engagement strategies to increase customer demand. Encouraging managers to supply healthy products with relatively high profitability and low procurement burden, such as wholegrain-rich foods, may be a potential first step towards sustainable changes in small food stores. Innovative distribution practices will also be needed to meet the needs of small stores and their customers, which may include the development of local distribution channels that make wholesale prices available for small purchases and offer frequent store delivery or pick-up options.

\section{Acknowledgements}

Acknowledgements: The authors would like to acknowledge Kristen Klingler and Nora Gordon at the Minneapolis Health Department for their continuous partnership on this work and their remarkable expertise on local small food stores. They would also like to acknowledge the extensive efforts of those who assisted with data acquisition and management, including Robin Friebur, Ross Anderson, Anna Bartholomay, Sarah Dzik and Lisa Murray. Finally, they thank the store managers who generously participated in this study. Financial support: This research was supported by the National Cancer Institute (C.E.C., grant number R25CA163184); the National Institute of Diabetes and Digestive and Kidney 
Diseases (M.N.L., grant number R01DK104348); and the Global Obesity Prevention Center (GOPC) at Johns Hopkins, through the Eunice Kennedy Shriver National Institute of Child Health and Human Development and the Office of the Director, National Institutes of Health (M.N.L., grant number U54HD070725). Data management support was provided by the National Center for Advancing Translational Sciences, National Institutes of Health (grant number UL1TR000114). The content is solely the responsibility of the authors and does not necessarily represent the official views of the National Institutes of Health. Funding agencies had no role in the design, analysis or writing of this article. Conflict of interest: The authors do not declare any conflicts of interest. Authorship: C.E.C. was responsible for formulating research questions and leading manuscript writing, and also supported carrying out the study from which these data originated. J.E.P. was responsible for performing data analysis, contributed to formulation of research questions and writing/revision of the manuscript, and supported carrying out the study from which these data originated. L.H. assisted in interpreting results, and made contributions to writing and revising the manuscript. D.J.E. guided and provided feedback on the analysis, assisted in interpreting results, and contributed to manuscript writing and revisions. M.N.L. was responsible for leading the overall study from which these data originated, including conception/design, funding acquisition and implementation, and gave feedback on analyses and writing/revision of the manuscript. Ethics of buman subject participation: This study was conducted according to the guidelines laid down in the Declaration of Helsinki and all procedures involving human subjects/patients were approved by the University of Minnesota. Verbal informed consent was obtained from all subjects. Verbal consent was witnessed and formally recorded.

\section{References}

1. Bodor JN, Ulmer VM, Dunaway LF et al. (2010) The rationale behind small food store interventions in low-income urban neighborhoods: insights from New Orleans. J Nutr 140, 1185-1188.

2. Franco M, Diez Roux AV, Glass TA et al. (2008) Neighborhood characteristics and availability of healthy foods in Baltimore. Am J Prev Med 35, 561-567.

3. Galvez MP, Morland K, Raines C et al. (2008) Race and food store availability in an inner-city neighbourhood. Public Health Nutr 11, 624-631.

4. Larson N, Story M \& Nelson M (2009) Neighborhood environments disparities in access to healthy foods in the US. Am J Prev Med 36, 74-81.

5. Morland K, Wing S, Roux A et al. (2002) Neighborhood characteristics associated with the location of food stores and food service places. Am J Prev Med 22, 23-29.

6. D'Angelo H, Suratkar S, Song H-J et al. (2011) Access to food source and food source use are associated with healthy and unhealthy food-purchasing behaviours among lowincome African-American adults in Baltimore City. Public Health Nutr 14, 1632-1639.
7. Cannuscio CC, Weiss EE \& Asch DA (2010) The contribution of urban foodways to health disparities.J Urban Health $\mathbf{8 7}$, 381-393.

8. Powell L, Slater S, Mirtcheva D et al. (2007) Food store availability and neighborhood characteristics in the United States. Prev Med 44, 189-195.

9. An R \& Sturm R (2012) School and residential neighborhood food environment and diet among California youth. Am J Prev Med 42, 129-135.

10. Castner L \& Henke J (2011) Benefit Redemption Patterns in the Supplemental Nutrition Assistance Program. Alexandria, VA: US Department of Agriculture, Food and Nutrition Service.

11. Shannon J (2014) What does SNAP benefit usage tell us about food access in low-income neighborhoods? Soc Sci Med 107, 89-99.

12. Morland K, Roux A \& Wing S (2006) Supermarkets, other food stores, and obesity - the Atherosclerosis Risk in Communities Study. Am J Prev Med 30, 333-339.

13. Morland K \& Evenson K (2009) Obesity prevalence and the local food environment. Health Place 15, 491-495.

14. Pearce J, Hiscock R, Blakely T et al. (2008) The contextual effects of neighbourhood access to supermarkets and convenience stores on individual fruit and vegetable consumption. J Epidemiol Community Health 62, 198-201.

15. Wall MM, Larson NI, Forsyth A et al. (2012) Patterns of obesogenic neighborhood features and adolescent weight: a comparison of statistical approaches. Am J Prev Med $\mathbf{4 2 ,}$ E65-E75.

16. Lent MR, Veur SV, Mallya G et al. (2015) Corner store purchases made by adults, adolescents and children: items, nutritional characteristics and amount spent. Public Health Nutr 18, 1706-1712.

17. Laska MN, Borradaile KE, Tester J et al. (2010) Healthy food availability in small urban food stores: a comparison of four US cities. Public Health Nutr 13, 1031-1035.

18. Cannuscio CC, Tappe K, Hillier A et al. (2013) Urban food environments and residents' shopping behaviors. Am J Prev Med 45, 606-614

19. Cavanaugh E, Mallya G, Brensinger C et al. (2013) Nutrition environments in corner stores in Philadelphia. Prev Med 56, 149-151.

20. Franco M, Diez-Roux AV, Nettleton JA et al. (2009) Availability of healthy foods and dietary patterns: the MultiEthnic Study of Atherosclerosis. Am J Clin Nutr 89, 897-904.

21. Adjoian T, Dannefer R, Sacks R et al. (2014) Comparing sugary drinks in the food retail environment in six NYC neighborhoods. J Community Health 39, 327-335.

22. Leslie TF, Frankenfeld CL \& Makara MA (2012) The spatial food environment of the DC metropolitan area: clustering, co-location, and categorical differentiation. Appl Geogr 35, 300-307.

23. Farley TA, Baker ET, Futrell L et al. (2010) The ubiquity of energy-dense snack foods: a national multicity study. Am J Public Health 100, 306-311.

24. Whitehouse A, Simon A, French SA et al. (2012) Availability of snacks, candy and beverages in hospital, community clinic and commercial pharmacies. Public Health Nutr 15, $1117-1123$.

25. Lucan SC (2015) Concerning limitations of foodenvironment research: a narrative review and commentary framed around obesity and diet-related diseases in youth. J Acad Nutr Diet 115, 205-212.

26. Gittelsohn J, Rowan M \& Gadhoke P (2012) Interventions in small food stores to change the food environment, improve diet, and reduce risk of chronic disease. Prev Chronic Dis 9, E59.

27. Gittelsohn J, Song H-J, Suratkar S et al. (2010) An urban food store intervention positively affects food-related 
psychosocial variables and food behaviors. Health Educ Behav 37, 390-402.

28. Song H-J, Gittelsohn J, Kim M et al. (2009) A corner store intervention in a low-income urban community is associated with increased availability and sales of some healthy foods. Public Health Nutr 12, 2060-2067.

29. Ayala GX, Laska MN, Zenk SN et al. (2012) Stocking characteristics and perceived increases in sales among small food store managers/owners associated with the introduction of new food products approved by the Special Supplemental Nutrition Program for Women, Infants, and Children. Public Health Nutr 15, 1771-1779.

30. Andreyeva T, Middleton AE, Long MW et al. (2011) Food retailer practices, attitudes and beliefs about the supply of healthy foods. Public Health Nutr 14, 1024-1031.

31. Gittelsohn J, Laska MN, Karpyn A et al. (2014) Lessons learned from small store programs to increase healthy food access. Am J Health Behav 38, 307-315.

32. O'Malley K, Gustat J, Rice J et al. (2013) Feasibility of increasing access to healthy foods in neighborhood corner stores. J. Community Health 38, 741-749.
33. City of Minneapolis, MN (2014) First staple foods ordinance in nation now setting stronger example for other cities. http://www.minneapolismn.gov/news/WCMS1P-133374 (accessed April 2015).

34. Andreyeva T, Luedicke J, Middleton AE et al. (2012) Positive influence of the revised special supplemental nutrition program for women, infants, and children food packages on access to healthy foods. J Acad Nutr Diet 112, 850-858.

35. Healthy Food Access Portal (2015) Health Food Financing Funds. http://www.healthyfoodaccess.org/funding/healthyfood-financing-funds (accessed May 2015).

36. Mariner WK \& Annas GJ (2013) Limiting 'sugary drinks' to reduce obesity - who decides? $N$ Engl J Med 368, 1763-1765.

37. Bustillos B, Sharkey JR, Anding J et al. (2009) Availability of more healthful food alternatives in traditional, convenience, and nontraditional types of food stores in two rural Texas counties. J Am Diet Assoc 109, 883-889.

38. Sharkey JR (2009) Measuring potential access to food stores and food-service places in rural areas in the US. Am J Prev Med 36, 4 Suppl., S151-S155. 